\title{
Optimal distributed generation placement using artificial intelligence for improving active radial distribution system
}

\author{
Fadhel A. Jumaa1, Omar Muhammed Neda' ${ }^{2}$, Mustafa A. Mhawesh ${ }^{3}$ \\ ${ }^{1,3}$ Al-Furat Al-Awsat Technical University, Iraq, Najaf \\ ${ }^{2}$ Department of Electrical Power Engineering, Sunni Diwan Endowment, Bagdad, Iraq
}

\begin{abstract}
Article Info
Article history:

Received Mar 5, 2021

Revised Jun 16, 2021

Accepted Jul 16, 2021

\section{Keywords:}

Distributed generator

MATLAB

Particle swarm optimization

Power loss

Voltage profile

ABSTRACT

There are several profits of distributed generator (DG) units which are believed for improving the safety of the distribution power grids. However, these profits can be maximized by ensuring optimum sizing and positioning of DG units because an arbitrary location of DG units may adversely affect and jeopardize power grids which could contribute to maximising of power loss and degradation of the voltage profile. Therefore, several approaches were suggested to ensure optimum position and size of DGs. The primary aim of this article is for establishing technique for optimum scheduling and operating of DG to lessen power loss, revamp voltage profile and overall network reliability. Artificial intelligence method called particle swarm optimization (PSO) is utilized for finding the best site and size of DG to lessen power loss and boost the voltage profile. In this paper, IEEE 33 distribution system is utilized to display applicability of PSO. The results of the PSO are compared with the results gotten by other methods in the literature. Finally, the results show that the PSO is superior than the other methods.
\end{abstract}

This is an open access article under the CC BY-SA license.

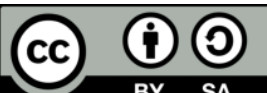

\author{
Corresponding Author: \\ Omar Muhammed Neda \\ Department of Electrical Power Engineering \\ Sunni Diwan Endowment \\ Bagdad, Iraq \\ Email: omar.neda88@gmail.com
}

\section{INTRODUCTION}

Conventional power stations, which are typically located close primary energy resources like coal, oil, and rivers, are primarily used for generating electricity in centralized power generating plants. The generated power is then transferred via long transmission lines to users linked to the distribution grids. In a distribution network power losses are high owing to high current and low voltage. One of the approaching generally adopted techniques to revamp voltage profile in addition to decrease loss of distribution grids is using distributed generation (DG) [1]. However, most of the electrical power infrastructures are aged and requires improvement/expansion to meet the increased demand for energy. However, the cost of expanding these networks can be avoided through several alternatives, such as capacitor allocation, network feeder reconfiguration, conductors upgrading, as well as the allocation of DG units and is the most inexpensive option [2].

DG is a renewable energy in small scale placed close to the load in distribution network. Connection of DG in distribution grid can lessen the power loss along with enhance the voltage profile. Electrical power consumption is on the increase, and environmental concerns, coupled with uncertainties over the reserve and cost of various types of fuel have led to an increased use of DG units in electrical distributive networks. DG units that are powered by solar, wind, geothermal, hydro, or biomass-sourced energy are considered as green 
power due to their little environmental impact, especially in terms of greenhouse gas emission. Although this trend has provided several opportunities in the power sector, it is imposed several limitations on the planning and control of distribution grids. Most of the benefits of allocating DG units include improving voltage stability, improving reliability and reducing power loss. However, several power abnormalities such as reverse power flows, subsequent feeder overloads, and excessive power losses can result from poorly planned and improperly operated DG units. With a significantly high DG penetration level, there could be an issue of voltage rise due to the reverse load flow of this voltage. Such dramatic power losses could also occur in a power system with DG due to due to inadequate sizing and incorrect positioning of DG units compared to a system without DG units. Thus, the operational problems encountered in most electrical power grids could be solved by integrating several DG units. All these benefits listed above, however, cannot be maximized and improved unless the optimum size and position of DG units is perfectly calculated [3].

Hence, there is a need to investigate the ways of achieving properly planned DG units sizing and allocation in a power system [4]. To achieve further improvements in optimal DG units integration into electrical networks, several studies have been dedicated to DG sizing and placement, with most of the studies focusing on voltage enhancement and minimizing losses [5]. A large number of methods were recommended for discovering the proper size and position of DG in distribution grids. First, conventional computational methods for optimal allocation of DG units in distribution grids were proposed [6], [7]. Although these techniques were reflected both constant in addition to variable loads and this technique overcomes the convergence issue but optimal sizing of DG units was not measured.

Secondly, based on the utilize of intelligent optimization methods for example simulated annealing (SA) that used for tackling the problem of DG allocation with the target of diminish power loss, contingency and emissions [8], [9]. Similarly, a strategy proposed in [10] for solving the same problem for reducing the total costs owing to power loss and the number of DG. An improved analytical (IA) technique in [11] and machine learning (ML) technique in [12]. Artificial bee colony (ABC) technique was offered for finding the appropriate DG allocation [13]. Cuckoo search (CS) technique also presented for solving this problem for power loss reduction [14]. In addition, just a few strategies are adopted with renewable DGs, such as in [15], ant lion optimization (ALO) process in [16], and a Backtracking search algorithm (BSA) in [17]. Flower pollination algorithm (FPA) is also utilized for determining size and location of DG [18]. Kamarposhti et al. proposed ABC for finding DGs and capacitors siting and siting for minimizing power loss and ENS [19].

This study proposes an optimization method called particle swarm optimization (PSO) for optimum sizing and positioning of DG units in power distribution grids, which was considered a complex optimization problem. It has significantly effective and superior in obtaining global solution and demonstrate the reliability and capability for overcoming the drawbacks of the conventional algorithms. This approach mainly aims at reducing power loss and improving the voltage profile in electrical distribution grids through finding the optimal operating of DG units using PSO technique. For computing the power loss and voltage, Backward/Forward Sweep algorithm is utilized in this study for radial distribution networks. This study will execute a detailed performance analysis on 33 bus network with the aim of establishing the robustness of the presented PSO method. Furthermore, the obtained results after putting the DG units in radial power network showed rapid enhancement in voltage profile and power loss lessening. The PSO is coded and applied through using MATLAB. Shortly, the allocation of two DG lead to better improvements of voltage profile and mitigation of power loss compared to allocation of one DG. Finally, the obtained results reflect significant enhancements in voltage profile improvement, power losses reduction and reliability improvements.

\section{PROBLEM FORMULATION}

In this work, PSO is for attaining the optimal placement of DG for lessening power loss $\left(P_{\text {Loss }}\right)$ and boosting voltage profile while dealing with some variables at the same time. $P_{\text {Loss }}$ in the electrical network can be written as shown in (1) [20]:

$$
P_{\text {Loss }}=\sum_{i}^{n}\left|I_{\text {branch (i) }}\right|^{2} * R_{i}
$$

where: $I_{\text {branch (i) }}$ : The branch current.

$R_{i}$ : The branch resistance.

The objective function for solving this problem is described as:

Minimize $P_{\text {Loss }}$

Bulletin of Electr Eng \& Inf, Vol. 10, No. 5, October $2021: 2345$ - 2354 
Subjected to:

- Power balance restriction:

$$
P_{D G}+P_{\text {subs }}=P_{\text {Loss }}+P_{\text {Load }}
$$

- Voltage restriction:

$$
V_{j}^{\min } \leq V_{j} \leq V_{j}^{\max },
$$

- DG restriction:

$$
P_{D G}^{\min } \leq P_{D G} \leq P_{D G}^{\max }
$$

- Line thermal restriction:

$$
\left|S_{l i}\right| \leq S_{l i} \max ,
$$

\section{PSO ALGORITHM}

PSO is a better type of a stochastic optimization algorithm, it has behavior like the behavior of animals when searching for food like fish schooling and bird flocking. Many researchers took in the consideration the use of this algorithm due to its substantiated strength, easiness at execution, and universal capability of exploration in numerous applications. The advantages of this algorithm are simple, fast, and it has a few number of parameters. In PSO technique, every possible solution represents as an individual. An individual signifies the candidate solution and every group of individuals signifies a swarm. Kennedy and Eberhart were first enhanced and developed this algorithm in 1995 [21], [22]. Each individual in the PSO algorithm has local best position $\left(P_{\text {best }}\right)$, and global best position $\left(G_{\text {best }}\right)$ [23]. The velocity $\left(V_{i}\right)$ and position $\left(X_{i}\right)$ from $P_{\text {best }}$ to $G_{\text {best }}$ of the agents will be changed by utilizing in (7) and (8) [24], [25]. The simple flowchart of the PSO process is exposed in Figure 1.

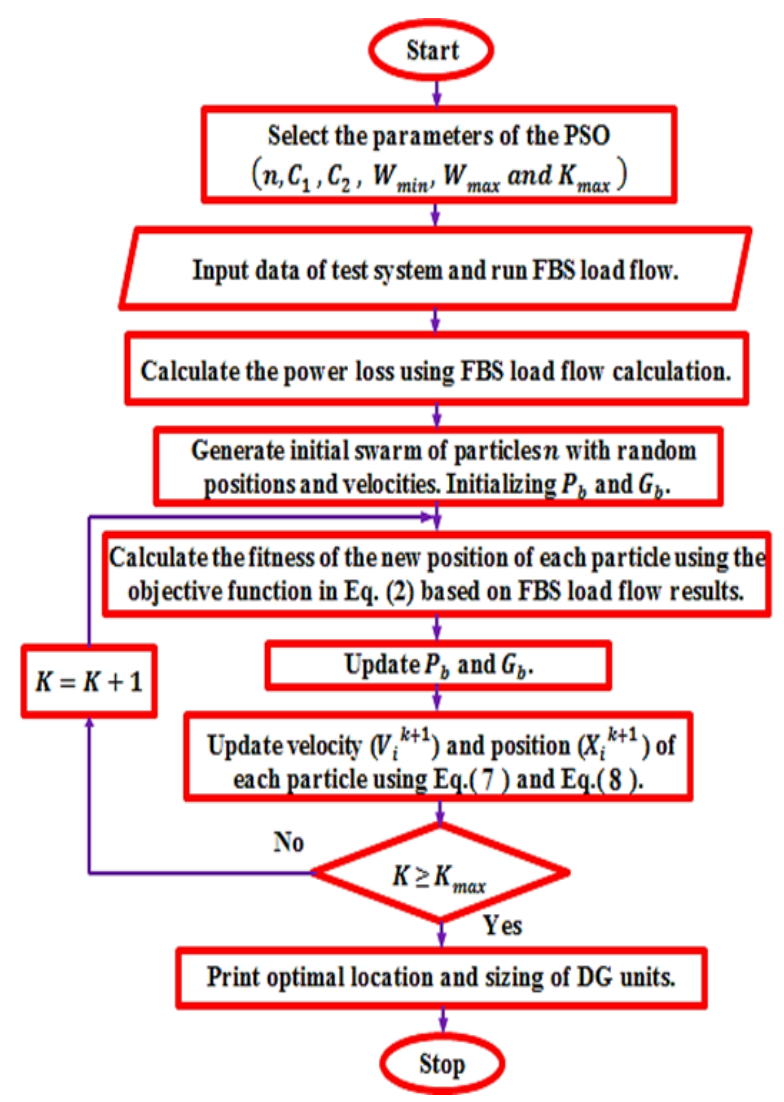

Figure 1. Flowchart of PSO algorithm 


$$
\begin{aligned}
& V_{i}^{k+1}=\left[W_{P S O} * V_{i}^{k}+C_{1} * R_{1} *\left(P_{\text {best }(i)}{ }^{k}-X_{i}^{k}\right)+C_{2} * R_{2} *\left(G_{\text {best }(i)}{ }^{k}-X_{i}^{k}\right)\right] \\
& X_{i}^{k+1}=X_{i}^{k}+V_{i}^{k+1}
\end{aligned}
$$

From the (7) and (8), $W_{P S O}$ is the PSO weight. $V_{i}$ characterizes the velocity. $C_{1}, C_{2}$ are the two learning factors. $R_{1}, R_{2}$ are the two random numbers. In this study, $\left(W_{P S O}\right)$ is reduced from $(0.9$ to 0.4$)$ linearly through iterations to attain balance between $G_{\text {best }}$ and $P_{\text {best }}$ as shown in (9) [26]:

$$
W_{P S O}=W_{\max }-\left(\frac{W_{\max }-W_{\min }}{K_{\max }}\right) * K
$$

From (9), $W_{\max }$ depicts the Max. value, $W_{\min }$ depicts the Min. value of weight, $K$ depicts the current iteration and $K_{\max }$ is the Max. iteration.

\section{RESULTS AND DISCUSSION}

The suggested method is completely based on PSO technique. The PSO technique is examined on IEEE 33 bus to demonstrate its applicability for calculating the best suitable size and site of one and two DG units simultaneously at the same time for raising voltage profile and lessening loss. The algorithm is presented and developed by MATLAB. Furthermore, DG is suggested in this work to be a solar photovoltaic [27]. The results for the IEEE 33 bus are listed in detail below.

\subsection{IEEE 33 bus}

This system was implemented to examine the PSO-based technique's ability in calculating the optimum position and scale of DGs. This system was displayed in Figure 2 while the whole system data are given in [28]. Three scenarios (without DG, with one DG and with two DG) are considered in this study for demonstrating the ability of the presented PSO algorithm in solving DG placement problem, which concluded with a comparative analysis of all instances.

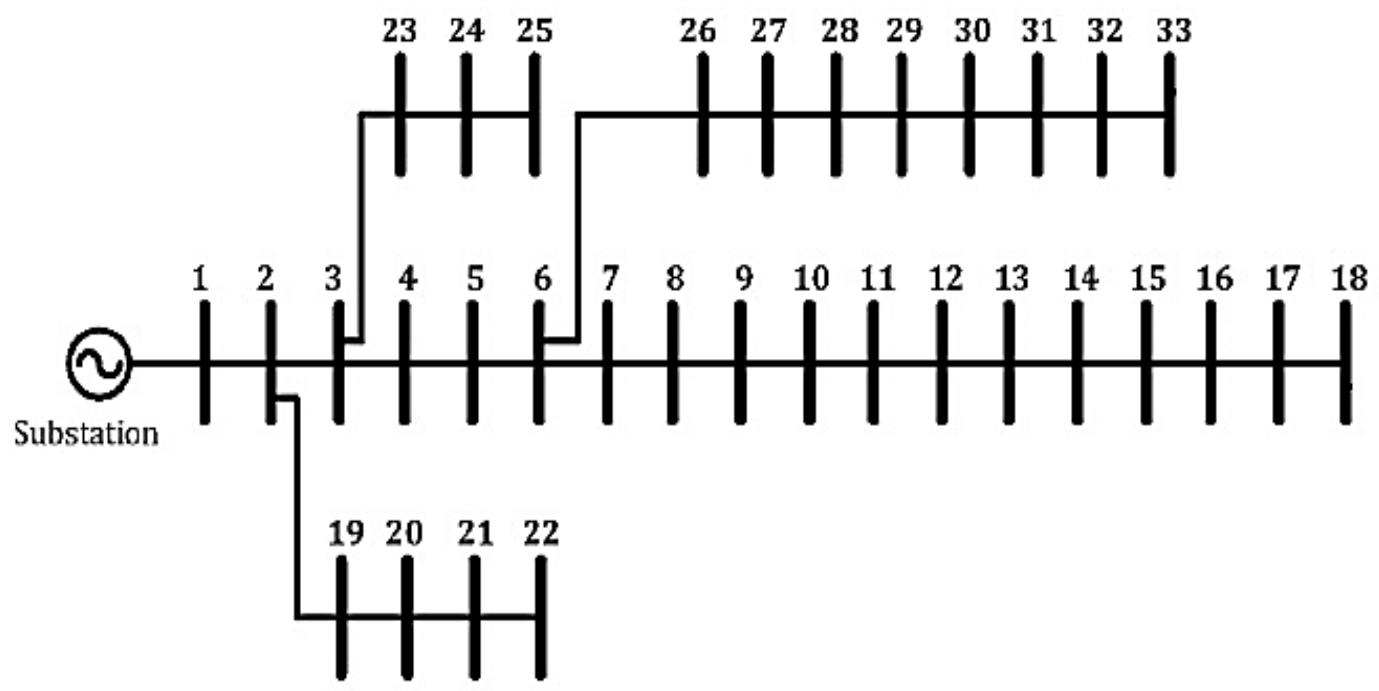

Figure 2. IEEE 33-bus radial system [28]

\subsubsection{Scenario 1: without DG}

This scenario demonstrates the initial results of power loss $(\mathrm{W})$ and voltage before installing any DG. Table 1 demonstrates the voltage and power loss for 33-bus network in each bus at base case. Additionally, the worst buses were 17, 18, 32 and 33 with a voltage of $0.9116,0.911,0.9155$ and 0.9097 , respectively. The system loads are: $\mathrm{P}_{\text {load }}=3.72 \mathrm{MW}$ and $\mathrm{Q}_{\text {load }}=2.3 \mathrm{MVAR}$. Also, the total loss was 202.26 KW before installing any DG. 
Table 1. Power loss and voltage profile for each bus for 33-bus without DG

\begin{tabular}{|c|c|c|}
\hline No. of Buses & Voltage (p.u.) & Power loss (W) \\
\hline 1 & 1.00000 & 202261.00 \\
\hline 2 & 0.99820 & 2640.6862 \\
\hline 3 & 0.99096 & 13397.784 \\
\hline 4 & 0.98630 & 7602.4172 \\
\hline 5 & 0.98071 & 3477.5313 \\
\hline 6 & 0.96738 & 7043.1781 \\
\hline 7 & 0.96205 & 1513.1615 \\
\hline 8 & 0.95729 & 4592.4839 \\
\hline 9 & 0.94687 & 6534.4699 \\
\hline 10 & 0.93726 & 4810.1137 \\
\hline 11 & 0.93619 & 4109.4482 \\
\hline 12 & 0.93426 & 1479.5418 \\
\hline 13 & 0.92630 & 5322.3010 \\
\hline 14 & 0.92222 & 1755.3187 \\
\hline 15 & 0.91908 & 2478.7296 \\
\hline 16 & 0.91560 & 1726.8665 \\
\hline 17 & 0.91165 & 3030.6017 \\
\hline 18 & 0.91102 & 1298.2161 \\
\hline 19 & 0.99089 & 4390.6963 \\
\hline 20 & 0.99023 & 37750.831 \\
\hline 21 & 0.98892 & 9525.4471 \\
\hline 22 & 0.98888 & 15829.370 \\
\hline 23 & 0.98592 & 8722.0355 \\
\hline 24 & 0.98417 & 17886.385 \\
\hline 25 & 0.98242 & 11846.824 \\
\hline 26 & 0.95952 & 1313.0623 \\
\hline 27 & 0.94162 & 1710.2359 \\
\hline 28 & 0.93036 & 7019.3304 \\
\hline 29 & 0.92242 & 4136.3900 \\
\hline 30 & 0.91946 & 3073.5107 \\
\hline 31 & 0.91340 & 3028.3078 \\
\hline 32 & 0.91158 & 725.75920 \\
\hline 33 & 0.90970 & 487.8580 \\
\hline
\end{tabular}

\subsubsection{Scenario 2: with one DG}

This scenario involved installing one DG in 33-bus to assess optimum size and position of this DG in a single step using PSO technique. Table 2 expressions the results acquired by using PSO including the optimal location and size of DG. For checking the ability and efficiency of the presented PSO technique over other techniques, the results attained by PSO are compared with those gotten by other techniques in the literature for instance genetic algorithm (GA) [29], harmony search algorithm (HSA) [30], Bat algorithm (BA) [31] and crow search algorithm (CSA) [32]. This comparison is made in order to achieve the aim of simultaneously reducing power loss and enhancing voltage profile of the IEEE 33 utilizing DG. The power loss $\left(P_{\text {Loss }}\right)$ is minimized substantially from 202.26 to $130.043 \mathrm{KW}$ after installing DG at size of $592.09 \mathrm{KW}$ on Bus 3 using PSO, which is the minimum power loss compared to that obtained by other literature algorithms as exposed in Table 2 and Figure 3. The percentage reduction in power loss is approximately about $35.7 \%$ compared to the scenario without any DG as displayed in Table 2. Table 2 and Figure 3 show that the offered PSO provides a lowest power loss and supreme results between all competitive algorithms.

Table 2. Investigating PSO efficiency for installing single DG unit over other approaches

\begin{tabular}{ccccc}
\hline Techniques & DG location & DG size $(\mathrm{KW})$ & $P_{\text {Loss }}(\mathrm{KW})$ & $P_{\text {Loss }}(\%)$ \\
\hline Base case & - & - & 202.26 & 0 \\
PSO & 3 & 592.09 & 130.034 & 35.7 \\
GA [29] & 6 & 2380 & 132.64 & 34.2 \\
HSA [30] & 18 & 894.1 & 144.23 & 28.6 \\
BA [31] & 15 & 816.3 & 137.20 & 32.1 \\
CSA [32] & 8 & 2534.7 & 132.10 & 34.6 \\
\hline
\end{tabular}

Furthermore, the voltage values of the worst buses $(17,18,32$ and 33$)$ in this system were raised from $0.9116,0.911,0.9155$, and 0.9097 to $0.94269,0.9424,0.9399$, and 0.93797 respectively, after installing DG unit. additionally, Figure 4 demonstrates the voltage profile. From this figure, it is noted that the voltage at all nodes were enhanced after installing one DG unit. 


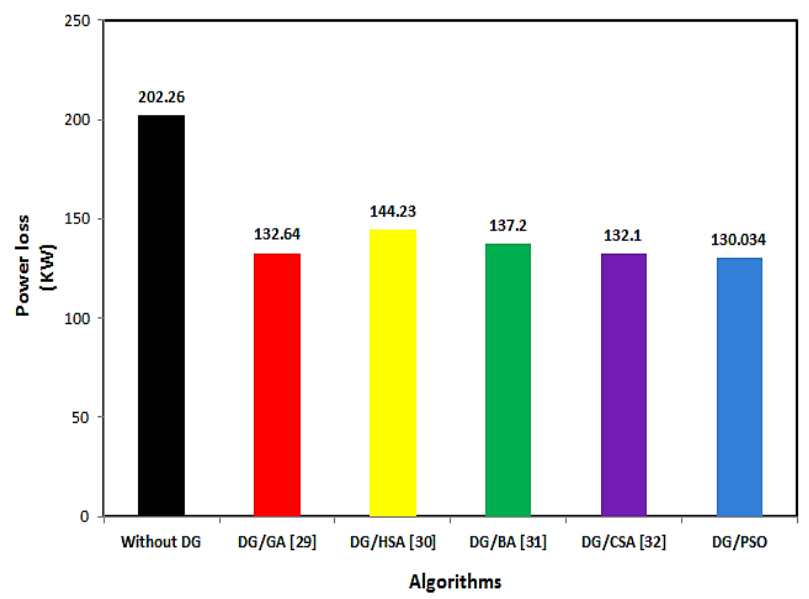

Figure 3. Comparisons of power loss after and before installing one DG unit for 33-bus

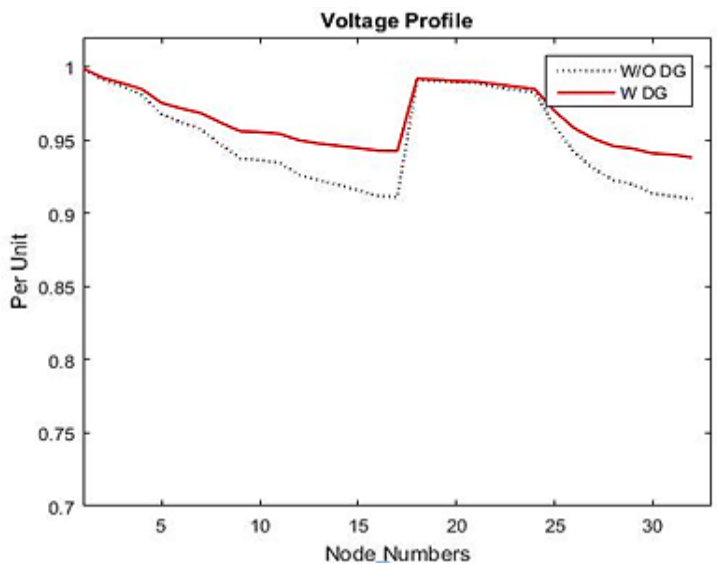

Figure 4. Voltage profile without and with one DG unit for 33-bus using PSO

\subsubsection{Scenario 3: with two DG}

This scenario involves installing two DG units in 33-bus for calculating the best size and location of each DG in one step using PSO technique. Table 3 displays the results gotten through using PSO. For checking the ability and efficiency of the presented PSO technique over other techniques, the results attained by PSO are also compared with those attained by other techniques in the literature for instance GA [29], HSA [30], BA [31] and CSA [32]. This comparison is made in order to achieve the aim of simultaneously reducing power loss $\left(P_{\text {Loss }}\right)$ and enhancing the voltage profile of IEEE 33 utilizing DG. The overall power loss is significantly reduced from 202.26 to $86.12 \mathrm{KW}$ following the installation of $438.55 \mathrm{KW}$ for the first DG on Bus 18 and $394.69 \mathrm{KW}$ for the second DG on Bus 33 using PSO, which is the minimum power loss compared to that obtained by other literature algorithms as presented in Table 3 and Figure 5. The reduction in power loss is approximately about $57.4 \%$ compared to the scenario without any DG. Table 3 and Figure 5 show that the offered PSO provides a lowest power loss and supreme results between all competitive algorithms.

Table 3. Investigating PSO efficiency for installing two DG unit over other approaches

\begin{tabular}{ccccc}
\hline Techniques & DG location & DG size $(\mathrm{KW})$ & $P_{\text {Loss }}(\mathrm{KW})$ & $P_{\text {Loss }}(\%)$ \\
\hline Base case & - & - & 202.26 & 0 \\
PSO & 18,33 & $438.55,394.69$ & 86.12 & 57.4 \\
GA [29] & 6,8 & 1718,840 & 96.58 & 52.2 \\
HSA [30] & 17,18 & $693.2,201.2$ & 141.14 & 30.2 \\
BA [31] & 15,25 & $952.35,952.35$ & 112.88 & 44.1 \\
CSA [32] & 16,26 & $1073.5,1326.2$ & 103.90 & 48.6 \\
\hline
\end{tabular}


The lowest voltages located at (buses $17,18,32,33$ ) in this system were improved from 0.9116 , $0.911,0.9155$, and 0.9097 respectively, to $0.95534,0.9552,0.9514$, and 0.95048 , respectively after installing two DG units. This represented a rapid enhancement compared to the first and second scenarios. Additionally, Figure 6 presents the voltage. From this figure, it is noted that the voltage at all nodes were further raised after installing two DG units.

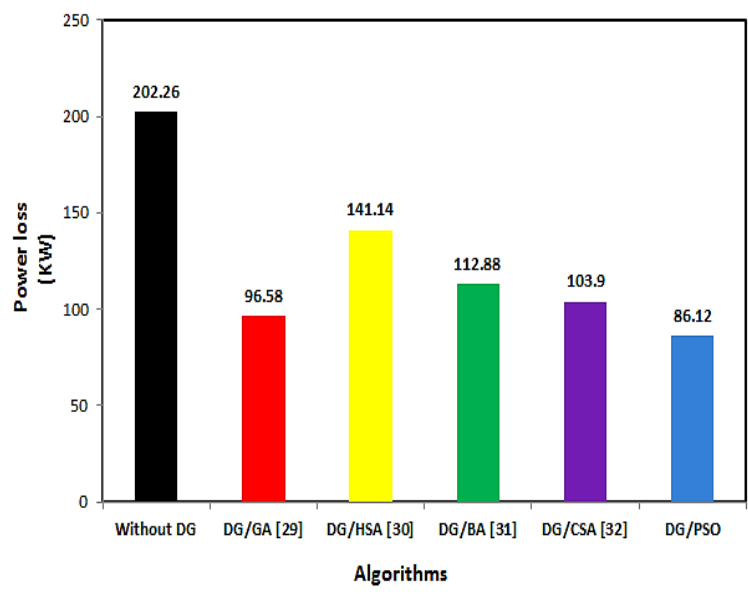

Figure 5. Comparisons of power loss after and before installing two DG unit for 33-bus

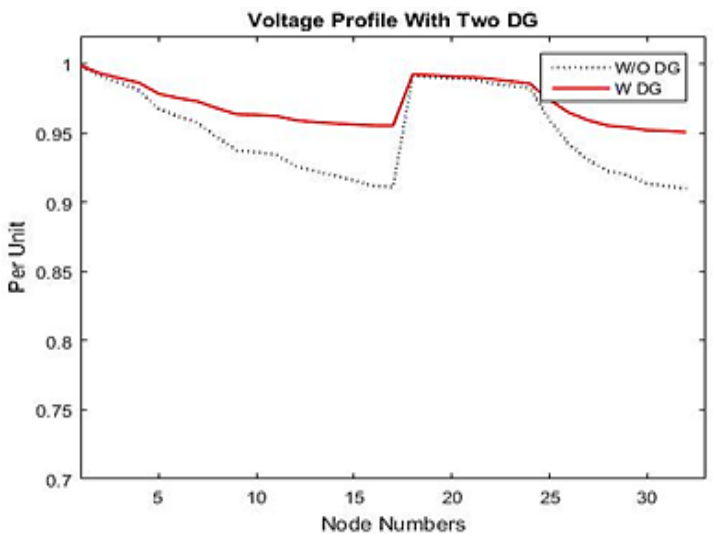

Figure 6. Voltage profile without and with two DG units for 33-bus using PSO

\subsubsection{Three scenarios comparison}

Optimum allocation and size of DG can enhance the voltages among all buses in the examined system; it can also substantially decrease the power loss. Additionally, the consistency and quality of the distribution network can be improved significantly, and it can make a contribution to consumer and supplier satisfaction. Although, allocating one DG unit will enhance the voltage with low values but allocating two DG units can produce further improvements in the voltage of all buses as shown in Figure 7. Moreover, Table 4 presents the most significant improvements in the minimum voltages buses for different scenarios. From this table, it was proved that the minimum voltage located at (buses 17, 18, 32, and 33) are significantly improved when installing two DG units.

Table 4. Voltage profile for 33-bus under three scenarios using PSO

\begin{tabular}{cccc}
\hline No. of buses & Scenario 1 & Scenario 2 & Scenario 3 \\
\hline 17 & 0.91165 & 0.94269 & 0.95534 \\
18 & 0.91102 & 0.94245 & 0.95525 \\
32 & 0.91158 & 0.93992 & 0.95147 \\
33 & 0.90970 & 0.93797 & 0.95048 \\
\hline
\end{tabular}


Additionally, Figure 8 compared the total power loss between the three scenarios previously described. The total power loss was observed to reduce from $202.26 \mathrm{KW}$ for the standard case to 130.043 $\mathrm{KW}$ with installing one DG unit and to $86.1258 \mathrm{KW}$ with installing two DG units. Also, from this figure, it was proved that the maximum power loss reduction was achieved when connecting two DG units. Finally, the proposed PSO displays best results in terms of minimum voltage, percentage power reduction (\%) and power loss $(\mathrm{KW})$ compared with other algorithms in the literature in all scenarios.

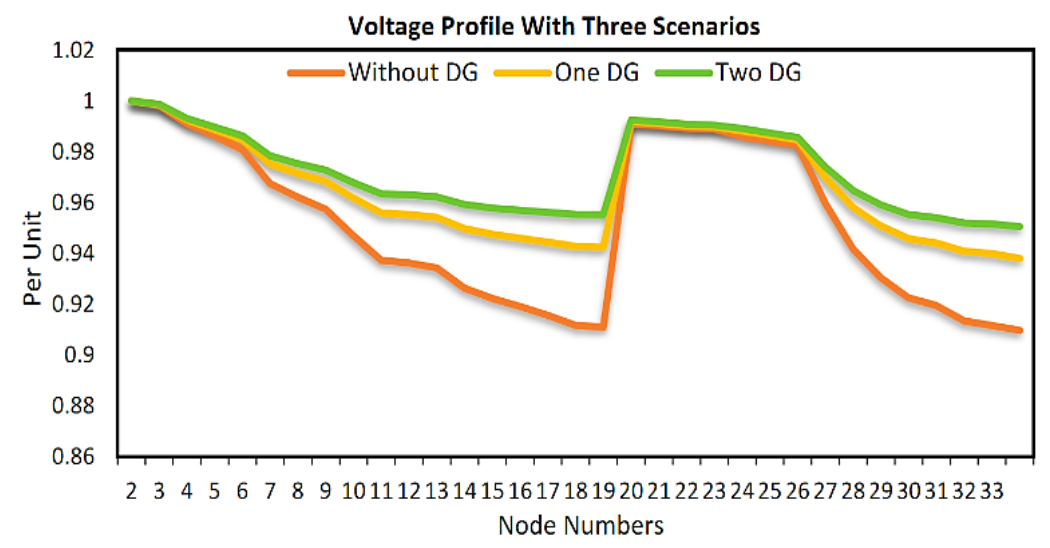

Figure 7. Voltage profile with three scenarios for 33-bus using PSO

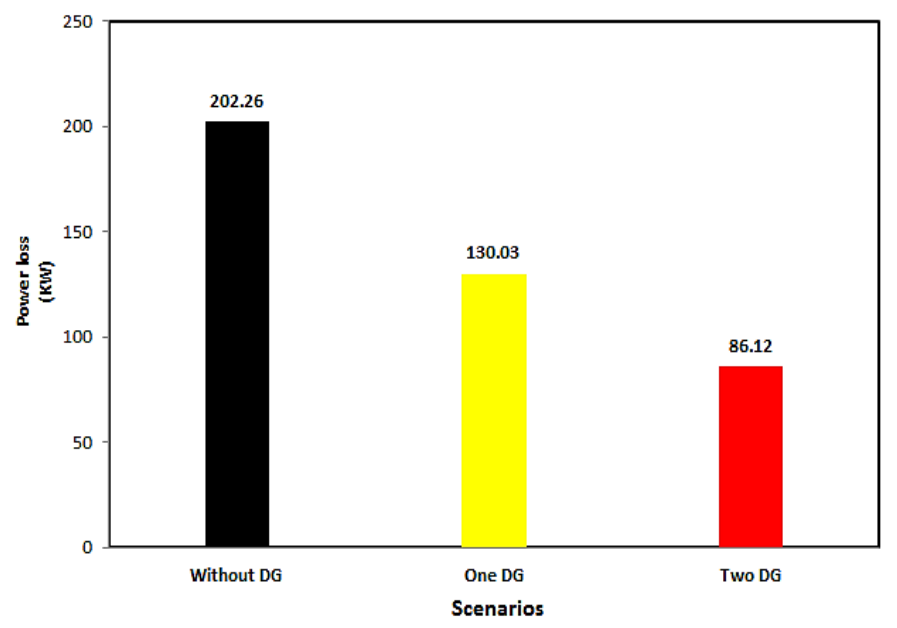

Figure 8. Comparison of power loss with three scenarios for 33-bus using PSO

\section{CONCLUSION}

In this study, PSO was applied to establish better size and site of DG units with the major aim of decreasing power loss and boosting the voltage profile in a power grid. The suggested PSO-based approach was applied as a useful optimization tool for decreasing the power loss $\left(P_{\text {Loss }}\right)$ in addition to revamping voltage profile by determining the top site and capacity of DGs. PSO was implemented to the IEEE-33-bus to demonstrate its validity. In addition, single and multiple DG deployment cases being conducted at presented test system and comparison to a system with no-DG. The results revealed that the capacity and position of DG had an vital influence in minimizing distribution power loss in addition to boosting voltage profile. The findings were contrasted with findings gotten by other algorithms in the literature. It is evident from the comparison that the solution suggested offers a remarkable result. In addition, these findings in this work show that the PSO is successful implemented in identifying the best site and capacity of the DG in all scenarios described. 


\section{REFERENCES}

[1] J. Casazza, J. Casazza, and F. Delea, "Understanding electric power systems: an overview of the technology and the marketplace," Hoboken. John Wiley \& Sons, 2003.

[2] N. H. Khan et al., "A Novel Modified Lightning Attachment Procedure Optimization Technique for Optimal Allocation of the FACTS Devices in Power Systems," in IEEE Access, vol. 9, pp. 47976-47997, 2021, doi: 10.1109/ACCESS.2021.3059201.

[3] J. P. Lopes, N. Hatziargyriou, J. Mutale, P. Djapic, and N. Jenkins, "Integrating distributed generation into electric power systems: A review of drivers, challenges and opportunities," Electric power systems research, vol. 77, no. 9, pp. 1189-1203, 2007, doi: 10.1016/j.epsr.2006.08.016.

[4] D. Q. Hung and N. Mithulananthan, "Multiple Distributed Generator Placement in Primary Distribution Networks for Loss Reduction," in IEEE Transactions on Industrial Electronics, vol. 60, no. 4, pp. 1700-1708, April 2013, doi: 10.1109/TIE.2011.2112316.

[5] T. T. Nguyen, T. T. Ngoc, T. T. Nguyen, T.-Phuc Nguyen, and N. A. Nguyen," Optimization of location and size of distributed generations for maximizing their capacity and minimizing power loss of distribution system based on cuckoo search algorithm," Bulletin of Electrical Engineering and Informatics, vol. 10, no. 4, pp. 1769-1776, 2021, doi: 10.13140/2.1.1594.9603.

[6] Z. Hamadouche, M. Khiat, and M. A. Iqbal," Intelligent voltage regulator for distributed generation-based network," Indonesian Journal of Electrical Engineering and Computer Science, vol. 23, no. 1, pp. 98-109, 2021, doi: 10.11591/ijeecs.v23.i1.pp\%25p.

[7] N. Acharya, P. Mahat, and N. Mithulananthan, "An analytical approach for DG allocation in primary distribution network," International Journal of Electrical Power \& Energy Systems, vol. 28, no. 10, pp. 669-678, 2006, doi: 10.1016/j.ijepes.2006.02.013.

[8] C.-R. Hwang, " Simulated annealing: theory and applications," Acta Applicandae Mathematicae, vol. 12, no. 1, pp. 108-111, 1988.

[9] T. Sutthibun and P. Bhasaputra, "Multi-objective optimal distributed generation placement using simulated annealing," ECTI-CON2010: The 2010 ECTI International Confernce on Electrical Engineering/Electronics, Computer, Telecommunications and Information Technology, 2010, pp. 810-813.

[10] A. I. Aly, Y. G. Hegazy and M. A. Alsharkawy, "A simulated annealing algorithm for multi-objective distributed generation planning," IEEE PES General Meeting, 2010, pp. 1-7, doi: 10.1109/PES.2010.5589950.

[11] D. Q. Hung and N. Mithulananthan, "Multiple Distributed Generator Placement in Primary Distribution Networks for Loss Reduction," in IEEE Transactions on Industrial Electronics, vol. 60, no. 4, pp. 1700-1708, April 2013, doi: 10.1109/TIE.2011.2112316.

[12] K. Mahmoud and M. Abdel-Nasser, "Fast yet Accurate Energy-Loss-Assessment Approach for Analyzing/Sizing PV in Distribution Systems Using Machine Learning," in IEEE Transactions on Sustainable Energy, vol. 10, no. 3, pp. 1025-1033, July 2019, doi: 10.1109/TSTE.2018.2859036.

[13] F. S. Abu-Mouti and M. E. El-Hawary, "Optimal Distributed Generation Allocation and Sizing in Distribution Systems via Artificial Bee Colony Algorithm," in IEEE Transactions on Power Delivery, vol. 26, no. 4, pp. 20902101, Oct. 2011, doi: 10.1109/TPWRD.2011.2158246.

[14] R. S. Al Abri, E. F. El-Saadany and Y. M. Atwa, "Optimal Placement and Sizing Method to Improve the Voltage Stability Margin in a Distribution System Using Distributed Generation," in IEEE Transactions on Power Systems, vol. 28, no. 1, pp. 326-334, Feb. 2013, doi: 10.1109/TPWRS.2012.2200049.

[15] M. Kefayat, A. L. Ara, and S. N. Niaki, "A hybrid of ant colony optimization and artificial bee colony algorithm for probabilistic optimal placement and sizing of distributed energy resources," Energy Conversion and Management, vol. 92, pp. 149-161, 2015, doi: 10.1016/j.enconman.2014.12.037.

[16] E. Ali, S. A. Elazim, and A. Abdelaziz, "Ant Lion Optimization Algorithm for Renewable Distributed Generations," Energy, vol. 116, pp. 445-458, 2016, doi: 10.1016/j.energy.2016.09.104.

[17] A. El-Fergany, "Optimal allocation of multi-type distributed generators using backtracking search optimization algorithm," International Journal of Electrical Power \& Energy Systems, vol. 64, pp. 1197-1205, 2015, doi: 10.1016/j.ijepes.2014.09.020.

[18] E. S. Oda, A. A. Abdelsalam, M. N. Abdel-Wahab, and M. M. El-Saadawi, "Distributed generations planning using flower pollination algorithm for enhancing distribution system voltage stability," Ain Shams Engineering Journal, vol. 8, no. 4, pp. 593-603, 2017, doi: 10.1016/j.asej.2015.12.001.

[19] M. A. Kamarposhti, S. M. M. Khormandichali and A. A. A. Solyman, " Locating and sizing of capacitor banks and multiple DGs in distribution system to improve reliability indexes and reduce loss using ABC algorithm," Bulletin of Electrical Engineering and Informatics, vol. 10, no. 2, pp. 559-568, 2021, doi: 10.11591/eei.v10i2.2641.

[20] S. R. Salkuti and N. R. Battu, "An effective network reconfiguration approach of radial distribution system for loss minimization and voltage profile improvement," Bulletin of Electrical Engineering and Informatics, vol. 10, no. 4, pp. 1819-1827, 2021, doi: 10.11591/eei.v10i4.2867.

[21] A. N. Hussain, A. A. Abdullah, and O. M. Neda, "Modified particle swarm optimization for solution of reactive power dispatch," Research Journal of Applied Sciences, Engineering and Technology, vol. 15, no. 8, pp. 316-327, 2018, doi: 10.19026/rjaset.15.5917.

[22] A. N. Hussain, A. A. Abdullah, and O. M. Neda," Optimal Capacitor Sizing for Reactive Power Optimization by Using a New Hybrid Algorithm Based on Merging of Chaotic Strategy with PSO Algorithm," Journal of Engineering and Applied Sciences, vol. 14, no. 7, pp. 2112-2123, 2018, doi: 10.36478/jeasci.2019.2112.2123. 
[23] O. M. Neda, "A new hybrid algorithm for solving distribution network reconfiguration under different load conditions," Indonesian Journal of Electrical Engineering and Computer Science, vol. 20, no. 3, pp. 1118-1127, 2020, doi: 10.11591/ijeecs.v20.i3.pp1118-1127.

[24] O. M. Neda, "Optimal coordinated design of PSS and UPFC-POD using DEO algorithm to enhance damping performance," International Journal of Electrical and Computer Engineering (IJECE), vol. 10, no. 6, pp. 61116121, 2020, doi: 10.11591/ijece.v10i6.pp6111-6121.

[25] A. N. Hussain, A. A. Abdullah, and O. M. Neda, "Improvement of Reactive Power Dispatch by Using Hybrid Intelligent Optimization Technique Based on Chaotic and PSO Algorithm," International Journal of Applied Engineering Research, vol. 13, no. 6, pp. 3932-3938, 2018.

[26] A. N. Hussain, A. A. Abdullah, and O. M. Neda, "Reactive Power Optimization Based on Artificial Intelligence," International Journal of Applied Engineering Research, vol. 13, no.8, pp. 5978-5988, 2018.

[27] M. A. Mhawesh and O. M. Neda, "A Review of the Photovoltaic System Converters and Algorithms," Journal of Global Scientific Research, vol. 6, no. 4, pp. 1297-1308, 2021.

[28] W. S. Tan, M. Y. Hassan, H. A. Rahman, M. P. Abdullah and F. Hussin, "Multi-distributed generation planning using hybrid particle swarm optimisation-gravitational search algorithm including voltage rise issue," IET Generation, Transmission \& Distribution, vol. 7, no. 9, pp. 929-942, 2013, doi: 10.1049/iet-gtd.2013.0050.

[29] T. Shukla, S. Singh, V. Srinivasaraob, and K. Naik, "Optimal sizing of distributed generation placed on radial distribution systems," Electric Power Components and Systems, vol. 38, no. 3, pp. 260-274, 2010, doi: $10.1080 / 15325000903273403$.

[30] R. Kollu, S. R. Rayapudi, and V. L. N. Sadhu, "A novel method for optimal placement of distributed generation in distribution systems using HSDO," European Transactions on Electrical Power, vol. 24, no. 4, pp. 547-561, 2014, doi: 10.1002/etep.1710.

[31] S. K. Sudabattula and M. Kowsalya, "Optimal allocation of solar based distributed generators in distribution system using Bat algorithm," Recent Trends in Engineering and Material Sciences, vol. 8, pp. 270-272, 2016, doi: 10.1016/j.pisc.2016.04.048.

[32] M. Abdelbadea, T. A. Boghdady and D. K. Ibrahim, "Enhancing active radial distribution networks by optimal sizing and placement of DGs using modified crow search algorithm," Indonesian Journal of Electrical Engineering and Computer Science, vol. 16, no. 3, pp. 1179-1188, 2019, doi: 10.11591/ijeecs.v16.i3.pp1179-1188. 